\title{
Deciphering the Curly Arrow Representation and Electron Flow for the 1,3-Dipolar Rearrangement between Acetonitrile Oxide and (1S,2R,4S)-2-Cyano-7-oxabicyclo[2.2.1]hept-5-en-2-yl Acetate Derivatives
}

\author{
Abel Idrice Adjieufack, Cyrille Nouhou Nana, Joseph Ketcha-Mbadcam, \\ Ibrahim Mbouombouo Ndassa,* Juan Andrés, Mónica Oliva, and Vicent Sixte Safont*
}

Cite This: ACS Omega 2020, 5, 22215-22225

Read Online

ACCESS 1

Wlll Metrics \& More

回国 Article Recommendations

SI Supporting Information

ABSTRACT: This study is focused on describing the molecular mechanism beyond the molecular picture provided by the evolution of molecular orbitals, valence bond structures along the reaction progress, or conceptual density functional theory. Using bonding evolution theory (BET) analysis, we have deciphered the mechanism of the 1,3-dipolar rearrangement between acetonitrile oxide and $(1 S, 2 R, 4 S)$-2-cyano-7-oxabicyclo[2.2.1] hept-5-en-2-yl acetate derivatives. The BET study revealed that the formation of the $\mathrm{C}-\mathrm{C}$ bond takes place via a usual sharing model before the $\mathrm{O}-\mathrm{C}$ one that is also formed in the halogenated species through a not very usual sharing model. The mechanism includes depopulation of the electron density at the N-C

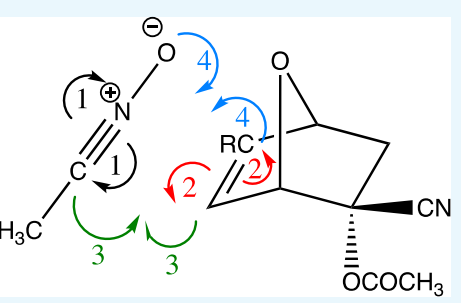
triple bond and creation of the $\mathrm{V}(\mathrm{N})$ and $\mathrm{V}(\mathrm{C})$ monosynaptic basins, depopulation of the former $\mathrm{C}-\mathrm{C}$ double bond with the creation of $\mathrm{V}(\mathrm{C}, \mathrm{C})$ basins, and final formation of the $\mathrm{V}(\mathrm{O}, \mathrm{C})$ basin associated with the $\mathrm{O}-\mathrm{C}$ bond. The topological changes along the reaction pathway take place in a highly synchronous way. BET provides a convenient quantitative method for deriving curly arrows and electron flow representation to unravel molecular mechanisms.

\section{INTRODUCTION}

Understanding the molecular mechanisms, that is, the processes of bond breaking and formation throughout the progress of a chemical reaction, and rationalizing chemical reactivity are the main goals of chemistry. ${ }^{1}$ Determining chemical reactions in time and space is very challenging because of the different length and time scales on which the nuclear dynamics take place.

An analysis of the chemical reactivity, that is, the processes involving the formation, breakage, and/or reorganization of chemical bonds along the reaction progress, is fundamental. To this end, the use of various theoretical and computational methods, such as those based on molecular orbital (MO), ${ }^{3-5}$ valence bond $(\mathrm{VB})^{6-8}$ calculations, and conceptual density functional theory (DFT)-based reactivity descriptors (hardness, polarizability, electrophilicity, etc.), which are based on derivatives of the electron density $\rho(\mathrm{r})$ and its energy, ${ }^{9-12}$ can be successfully demonstrated. In this context, chemical reactivity can be investigated by electronic structure calculations using two main approaches: those based on the analysis of MOs and $\rho(\mathrm{r})$. It is important to stress that the MOs or the Kohn-Sham orbitals in DFT are merely mathematical constructs that are used to obtain a route to an approximate solution to the Schrödinger equation. Furthermore, because an arbitrary unitary transformation of a wave function does not alter its amplitude (probability density) or consequently any observable properties, an MO basis used to build the wave function is not only nonunique but is also not observable ${ }^{13,14}$ and is limited by the equivalence of different MO choices and the multiple MO configurations (multireference wave functions) needed to describe covalent bond breaking. ${ }^{15-18}$

A way to provide robust and rigorous formalism based on quantum mechanics and overcome the abovementioned inconsistencies is to examine the information contained in the analysis of the topology of molecular scalar fields, which condense the chemically relevant information obtained from quantum calculations into an observable computed from it, such as electron density. ${ }^{19,20}$ This procedure makes it possible to perform a real-space partitioning of the molecular space using functions of the electronic density and/or its derivatives and is known as quantum chemical topology (QCT), named by Popelier, ${ }^{21,22}$ where topological analysis on scalar fields, including the most prominent approach, quantum theory of atoms in molecules (QTAIM), ${ }^{23,24}$ and the electron localization function (ELF), ${ }^{25,26}$ is employed. The ELF performs a topological analysis of the same-spin pair probability density and thus generates basins of localized electron pairs, enabling a

Received: May 20, 2020

Accepted: August 6, 2020

Published: August 24, 2020 
Scheme 1. Regioisomeric and Diastereofacial Isomeric Channels Associated with the Reactions between 1 and $2 a-c$
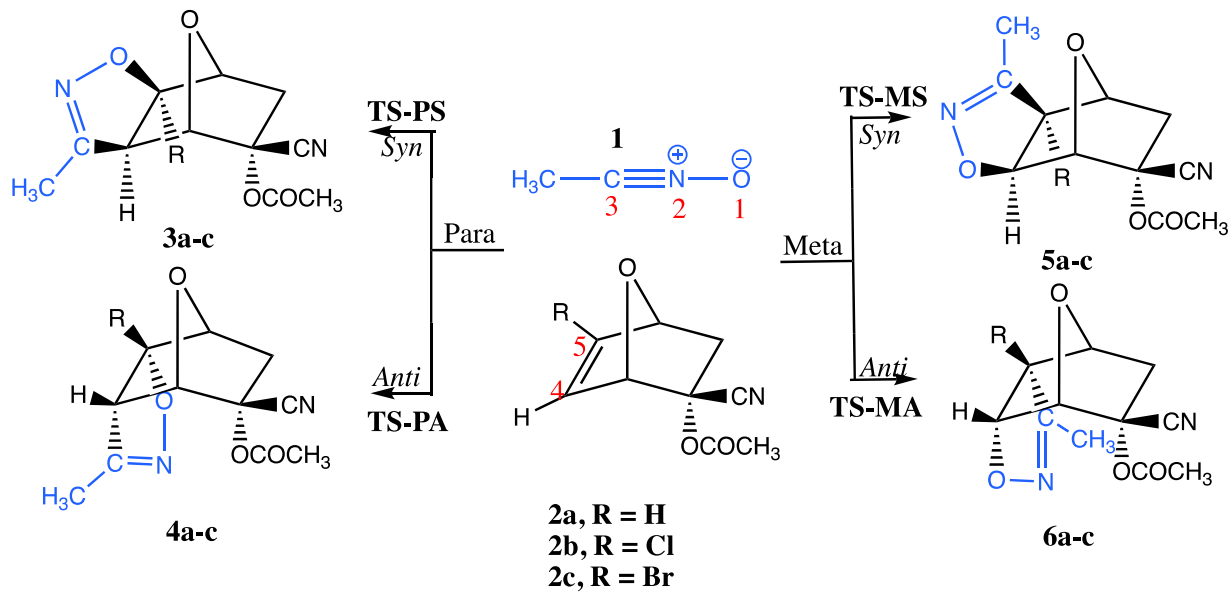

$\mathbf{2 a}, \mathbf{R}=\mathbf{H}$

$2 \mathrm{c}, \mathbf{R}=\mathbf{B r}$

6a-c

chemically intuitive partition of molecular regions involving strong electron pairing such as atom bonds and lone pairs. In particular, there is a one-to-one correspondence between the VSEPR domains, localized electron pairs, and the localization basins of the ELF, the function being soundly interpreted in terms of local excess kinetic energy because of the Pauli repulsion. $^{26-28}$

Using the topology of the electron density, Krokidis and Silvi were the pioneers in the development of the theoretical background leading to the establishment of the bonding evolution theory (BET) in order to describe the molecular mechanism of a reaction in terms of creation or annihilation of electronic domains. ${ }^{26,29} \mathrm{BET}$ is a solid procedure based on the combination of the $\operatorname{ELF}^{25,30}$ and Thom's mathematical catastrophe theory $(\mathrm{CT}) .^{31} \mathrm{BET}$ allows us to perceive electronic rearrangement and bonding changes taking place along a reaction pathway. ${ }^{32-42}$ During the BET analysis, only three types of bifurcation catastrophes have been found in chemical reactivity and two of them have been identified in the present study: the fold catastrophe, corresponding to the creation or annihilation of two critical points of different parity, and the cusp catastrophe, which transforms one critical point into three (and vice versa) such as in the formation or the breaking of a covalent bond.

In 2004, our research group published the first study on the molecular mechanism of the 1,3-dipolar cycloaddition by employing BET. ${ }^{43}$ Very recently, illustrative examples were presented to show how BET is capable of adequately predicting the bond-breaking/-forming process and the order and direction of the electron density flow of a given chemical rearrangement, thereby providing quite valuable information on the curly arrow representation of the reaction mechanism when studying reaction mechanisms at the elementary level by different authors. $32,42,44-59$

The $[3+2]$ cycloaddition reactions were classified into four types depending on the electronic structure of the involved three-atom component (TAC). ${ }^{60}$ In particular, nitrile oxides were classified as zwitterionic TACs, ${ }^{61}$ and their reactivity has been studied in several studies. Although they all follow the same pattern, some differences can be found in the way the bonds are formed. Thus, the reaction between benzonitrile oxide and $\mathrm{N}$-vinylpirrole ${ }^{62}$ takes place with the formation of the $\mathrm{C}-\mathrm{C}$ single bond through the coupling of two monosynaptic basins, or pseudoradical centers, ${ }^{63}$ created at the two interacting carbon atoms, followed by the formation of the $\mathrm{O}-\mathrm{C}$ single bond that takes place through the donation of some electron density of the nitrile oxide oxygen lone pairs and the electron density of the $\mathrm{C}$ pseudoradical center of the vinyl group. The same behavior was found, for instance, in the study of substituted nitrile oxides with methyl acrylate. ${ }^{64}$ However, the reaction between trifluoroacetonitrile $\mathrm{N}$-oxide and 2,2,4,4tetramethyl-3-thioxocyclobutan-1-one ${ }^{65}$ takes place via the $\mathrm{C}$ to $\mathrm{S}$ and $\mathrm{O}$ to $\mathrm{C}$ coupling of the corresponding pseudoradical centers, while for the reaction between tormentosin and benzonitrile oxide, ${ }^{66}$ it was found that the $\mathrm{C}-\mathrm{C}$ bond is formed according to the usual sharing model, and the $\mathrm{O}-\mathrm{C}$ bond forms via a donation model without the formation of the pseudoradical center on the carbon atom. Finally, phenyl nitrile oxide reacts with $(\mathrm{R})$-carvone, ${ }^{67}$ in a process beginning with the formation of the $\mathrm{C}-\mathrm{C}$ single bond by sharing part of the nonbonding electron density of one of the carbon atoms and that of the pseudoradical center on the other carbon atom, while the formation of the second $\mathrm{O}-\mathrm{C}$ single bond takes place by donation of nonbonding electron density of the $\mathrm{O}$ oxygen to the small amount of nonbonding electron density created at the $\mathrm{C}$ carbon.

To further understand these types of reactions and unravel the molecular details, in this study, we have selected a complex rearrangement reaction and we will clarify, for the first time, the molecular mechanism of the 1,3-dipolar reaction between nitrile oxide and $(1 S, 2 R, 4 S)$-2-cyano-7-oxabicyclo[2.2.1] hept5-en-2-yl acetate derivatives, which was reported by Arjona et al. ${ }^{68} 30$ years ago. The mechanism underlying this reaction remained unknown for years, and we have shown in the present study that the presence of a halogen atom changes the way in which the $\mathrm{O}-\mathrm{C}$ bond is formed.

Very recently, we were able to show how effectively BET retrieves and visualizes curly arrows in the cycloaddition reaction of cyclic nitrones. ${ }^{69}$ In the present study, we include a complete BET analysis and recover the curly arrow representation and the corresponding electron flow. Therefore, an added value of the present work with respect to previous articles on the description of reaction mechanisms of similar chemical rearrangements is to disclose how curly arrows meet electron density transfers and electron flow along the rearrangement progress.

We have focused on the proposed reaction mechanisms in an attempt to highlight the key concepts that are emerging on the basis of this study to disclose the steric and electronic factors that govern the outcome of these organic trans- 
Table 1. Relative (to the Separate Reactants) Total Energies (kcal/mol) ${ }^{a}$

\begin{tabular}{|c|c|c|c|c|c|c|}
\hline \multirow[b]{2}{*}{ species } & \multicolumn{3}{|c|}{ in vacuo } & \multicolumn{3}{|c|}{ in benzene } \\
\hline & $2 a, R=H$ & $\mathbf{2 b}, \mathrm{R}=\mathrm{Cl}$ & $2 \mathrm{c}, \mathrm{R}=\mathrm{Br}$ & $2 a, R=H$ & $\mathbf{2 b}, \mathrm{R}=\mathrm{Cl}$ & $2 \mathrm{c}, \mathrm{R}=\mathrm{Br}$ \\
\hline TS-PS & 7.88 & 9.05 & 9.21 & 9.15 & 10.13 & 10.33 \\
\hline TS-PA & $15.62(7.74)$ & $18.45(9.40)$ & $18.88(9.67)$ & $16.51(7.36)$ & $19.03(8.90)$ & $19.47(9.14)$ \\
\hline TS-MS & 9.48 & 10.13 & 10.06 & 10.36 & 11.35 & 11.32 \\
\hline TS-MA & $15.66(6.18)$ & $19.16(9.03)$ & $19.21(9.15)$ & $16.80(6.44)$ & $20.48(9.13)$ & $20.57(9.25)$ \\
\hline 3 & -57.89 & -58.53 & -57.48 & -57.02 & -57.50 & -56.35 \\
\hline 4 & $-54.77(3.12)$ & $-56.21(2.32)$ & $-54.97(2.51)$ & $-53.43(3.59)$ & $-54.91(2.59)$ & $-53.62(2.73)$ \\
\hline 5 & -56.26 & -55.48 & -54.90 & -55.63 & -54.26 & -53.65 \\
\hline 6 & $-55.49(0.77)$ & $-54.43(1.05)$ & $-53.85(1.05)$ & $-54.13(1.50)$ & $-52.84(1.42)$ & $-52.23(1.42)$ \\
\hline
\end{tabular}
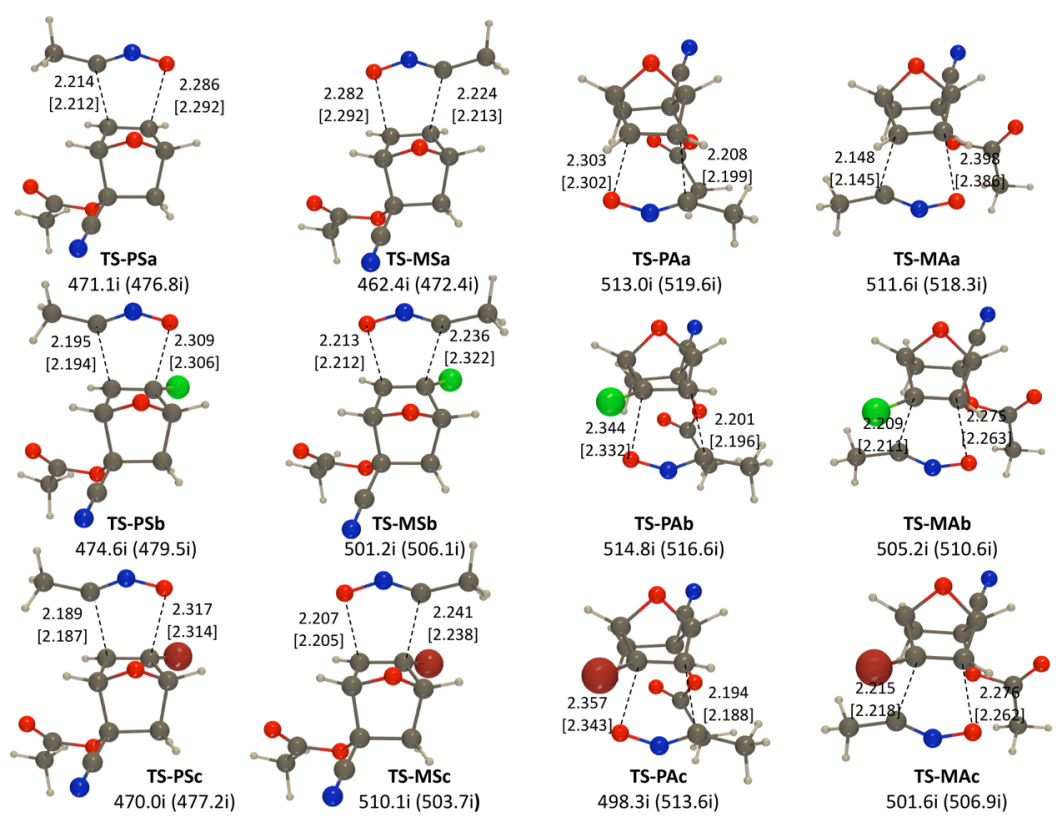

Figure 1. Optimized geometries for the TSs. The values of the key bond distances in vacuo are indicated while the values in brackets stand for the optimized TSs in benzene (in $\AA$ ). The imaginary frequency values $\left(\mathrm{cm}^{-1}\right)$ for each TS in the gas phase and, in parenthesis, in benzene are indicated.

formations. This will allow us to address and answer some new questions: (a) where and how does charge transfer take place along the reaction progress? (b) how does electron density rearrange and how can this rearrangement be associated with chemical events such as the breaking/forming of chemical bonds along the reaction progress? (c) how could the electronic reorganization proceed along the reaction path? Or, in other words, what types of catastrophes and structural stability domains (SSDs) appear along each reaction pathway during the BET analysis? and (d) how can the substitution of the $\mathrm{H}$ atom in the $\mathrm{C5}$ position of $(1 S, 2 R, 4 S)$-2-cyano-7oxabicyclo[2.2.1] hept-5-en-2-yl acetate by a halogen atom $(\mathrm{Cl}$ or $\mathrm{Br}$ ) change the $\mathrm{BET}$ description of the molecular mechanism?

\section{RESULTS AND DISCUSSION}

As mentioned above, the goal of the present paper is to study the electronic rearrangement taking place along the reaction between acetonitrile oxide (1) and $(1 S, 2 R, 4 S)$-2-cyano-7oxabicyclo[2.2.1] hept-5-en-2-yl acetate derivatives $(\mathbf{2 a - c})$. Considering the nonsymmetry of unsaturated alkenes, four reaction channels via syn and anti-attacks and para and meta regioisomeric approaches of nitrile oxide on 7-oxanorbornenic derivatives can be envisaged, as indicated in Scheme 1. In this way, the channels through TS-PSa-c, TS-PAa-c, TS-MSa-c, and TS-MAa-c are possible.

Table 1 displays the relative (to the separate reactants) energies of all species involved in this cycloaddition. The whole set of energetic parameters is reported in the Supporting Information (Tables S1 and S2). From Table 1, the analysis of activation energies shows that the para channels present lower activation barriers than the corresponding meta channels. A local conceptual density functional theory analysis (see the Supporting Information) allows us to ascertain that the most favorable electrophile-nucleophile interaction will take place between the $\mathrm{O} 1$ oxygen atom of $\mathbf{1}$ and the $\mathrm{C} 5$ carbon atom of $\mathbf{2 a}-\mathbf{c}$, and consequently, the activation barriers along the para channels (in which the O1-C5 bond is formed) are lower than the corresponding barriers along the meta channel, in which the $\mathrm{O} 1-\mathrm{C} 4$ bond is formed instead.

In addition, the TSs for the syn attack are always more stable than the TSs for the anti processes. This result could a priori be considered as unexpected. However, two reasons can be argued that explain this behavior: on the one hand, the favorable interaction that takes place in the syn attacks, between the partial positive charge on the $\mathrm{N}$ atom of the acetonitrile oxide and the partial negative charge on the bridge oxygen. On the other hand, the unfavorable steric arrangement 
observed in the anti attacks that places the methyl groups (of the acetonitrile oxide and the acetate residue) close to each other, disfavoring the TSs for the anti paths (Figure 1). Therefore, our results are able to explain the experimental outcome of the reaction between $\mathbf{1}$ and $2 a-c$ that affords a main, or even unique, product species $3 a-c{ }^{68}$

The syn-to-anti difference in activation energies for the para and meta regioisomeric reaction pathways between $\mathbf{1}$ and $\mathbf{2 a}$ in vacuo (in parenthesis, the values in benzene) is $7.74(7.36)$ and $6.18(6.44) \mathrm{kcal} / \mathrm{mol}$, respectively. It is worth noting that the activation energy variations observed in benzene are very similar to those found in vacuo. For case $\mathbf{2 b}$, in which the hydrogen atom on $\mathrm{C} 5$ of $\mathbf{2 a}$ is substituted by a chlorine atom, the difference becomes 9.40 (8.90) and 9.03 (9.13) kcal/mol, respectively. For case $2 \mathrm{c}$, in which the hydrogen atom on $\mathrm{C} 5$ of $2 \mathrm{a}$ is replaced by bromine, the difference becomes 9.67 (9.14) and 9.15 (9.25) $\mathrm{kcal} / \mathrm{mol}$, respectively. Therefore, the paths that are not the para-syn path are even more disfavored, and this result is also in agreement with the experimental data: ${ }^{68}$ when the $\mathrm{H}$ atom is replaced by $\mathrm{Cl}$ or $\mathrm{Br}, 3 \mathbf{b}$ or $3 \mathbf{c}$ is the only detectable product. The activation barriers for the reactions involving halogenated $\mathbf{2 b}$ and $\mathbf{2 c}$ compounds are slightly higher than those computed for $\mathbf{2 a}$ probably because of small repulsion between the lone pairs of the halogen atom and the lone pairs of the oxygen atom (para approaches) or to some steric hindrance between the methyl group and the halogen atom (meta approaches). On the other hand, the activation energies increase in all cases on comparing the in vacuo values with those obtained in benzene probably because of a slightly better solvation of the reagents than the TSs.

As for the reaction energies, it has also been found that the $3 \mathbf{a}-\mathbf{c}$ products are clearly more stable than the others and therefore they are also the thermodynamically preferred products, in accordance with the experimental observations. Additionally, it is found that the syn products are always more stable than the corresponding anti products along both the meta and the para channels. On the other hand, the values of the reaction energies are always less negative in benzene than in vacuo, and the differences in reaction energies between the anti and syn channels are slightly greater in benzene than in vacuo.

The relative enthalpies, entropies, and Gibbs energies of the stationary points found along the reactions studied here are reported in the Supporting Information (Table S3), all of them calculated in benzene. As for the enthalpies, the activation values are generally slightly higher than the activation energies, while the reaction enthalpies are a little less negative. The Gibbs energy activation values are much higher than the activation enthalpies or the activation energies because the entropic term disfavors the reaction, as can be seen. Moreover, the Gibbs energy reaction values are less negative for the same reason.

The optimized geometries of the 12 TSs corresponding to these reactions between $\mathbf{1}$ and $\mathbf{2 a}-\mathbf{c}$ are depicted in Figure 1 . In general, the lengths of the $\mathrm{C}-\mathrm{C}$-forming bonds are shorter than those of the $\mathrm{C}-\mathrm{O}$-forming bonds, except in the cases of TS-MSb and TS-MSc. However, in the corresponding products, the $\mathrm{C}-\mathrm{C}$ distances will always be longer than those of $\mathrm{C}-\mathrm{O}$, by ca $0.1 \AA$. These observations suggest that the $\mathrm{C}-\mathrm{C}$ bonds will be formed prior to the $\mathrm{C}-\mathrm{O}$ bonds. The substitution of hydrogen by halogen atoms slightly increases the lengths of the $\mathrm{C}-\mathrm{C}$-forming bonds in the meta-syn and para-anti cases and decreases those in the other two, while the lengths of the $\mathrm{C}-\mathrm{O}$-forming bonds increase in the para-syn and the meta-anti cases and decrease in the other two cases.

The inclusion of the benzene solvent in the calculations does not significantly affect the distance values or the observed tendencies.

BET Analysis for the Syn Attack along the Para Channel. Mechanism of the Reaction between 1 and $2 a$. As explained earlier, the syn processes are always energetically favored with respect to the anti processes. We therefore studied these syn processes further using the BET analysis along the reaction path. An analysis of the results reveals the existence of five SSDs for the para-syn approach path along the reaction between $\mathbf{1}$ and $\mathbf{2 a}$, as we can see in Figures 2 and 3 .

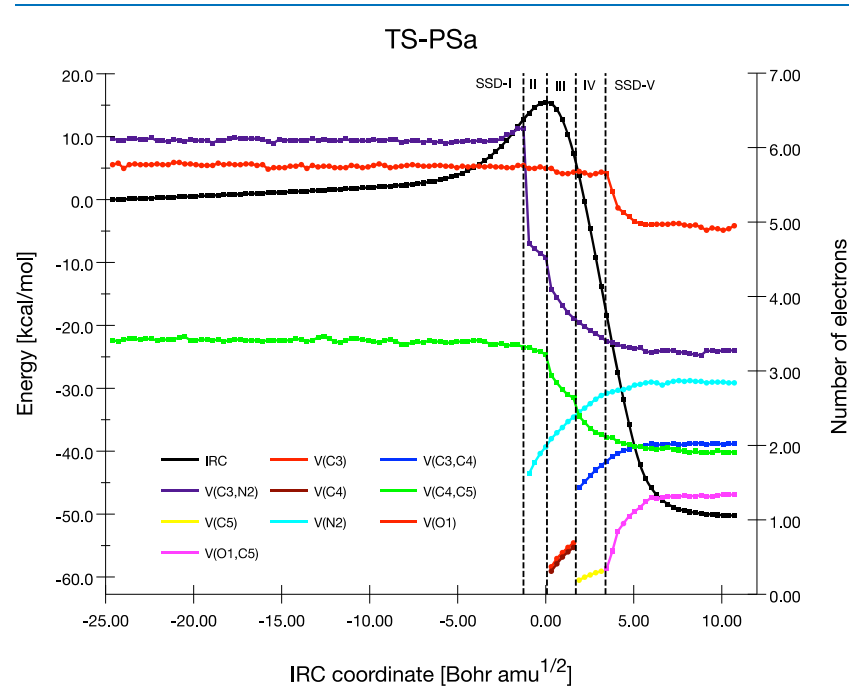

Figure 2. Population (in electrons) evolution of selected basins along the pathway involving the TS-PSa of the reaction between $\mathbf{1}$ and $\mathbf{2 a}$. The relative energy (in $\mathrm{kcal} / \mathrm{mol}$ ) along the IRC is represented by black lines with dots.

The first SSD reflects the sum of the reagent topologies: one $\mathrm{V}(\mathrm{C} 3, \mathrm{~N} 2)$ disynaptic basin with a 6.12 |e $\mid$ population corresponding to the $\mathrm{N} 2-\mathrm{C} 3$ triple bond, one $\mathrm{V}(\mathrm{O} 1)$ monosynaptic basin with $5.77 \mathrm{lel}$, illustrating the lone pairs for the oxygen atom around the acetonitrile oxide, and one $\mathrm{V}(\mathrm{C} 4, \mathrm{C} 5)$ disynaptic basin with a 3.41 lel population for the $\mathrm{C}-\mathrm{C}$ double bond of $\mathbf{2 a}$.

The first catastrophe along the reaction pathway is one of the fold-F types, corresponding to the creation of a V(N2) monosynaptic basin on the $\mathrm{N} 2$ atom. The population of the new $\mathrm{V}(\mathrm{N} 2)$ monosynaptic basin is $1.62 \mathrm{lel}$ at the beginning and grows until 1.98 lel at the end of the domain SSD-II. The population of this new $\mathrm{V}(\mathrm{N} 2)$ monosynaptic basin comes from the drop in the $\mathrm{V}(\mathrm{C} 3, \mathrm{~N} 2)$ basin, which shows a reduction of 1.55 lel during the first step of the SSD-II domain. The reduction of the $\mathrm{V}(\mathrm{N} 2, \mathrm{C} 3)$ basin continues along the SSD-III domain and leads to the appearance of the $\mathrm{V}(\mathrm{C} 3)$ basin with a population of 0.37 lel. In addition to this $\mathrm{V}(\mathrm{C} 3)$ monosynaptic basin, we also notice the appearance of the $\mathrm{V}(\mathrm{C} 4)$ monosynaptic basin with a population of 0.31 lel. This population is the result of the reduction in the population of the $\mathrm{V}(\mathrm{C} 4, \mathrm{C} 5)$ basin, which underwent a loss of $0.28 \mathrm{lel}$ at the beginning of the domain.

At the end of the SSD-III domain, these two monosynaptic basins that are necessary for the formation of the $\mathrm{C} 3-\mathrm{C} 4$ bond $^{60}$ have accumulated a population of 0.61 lel for $\mathrm{V}(\mathrm{C} 3)$ 

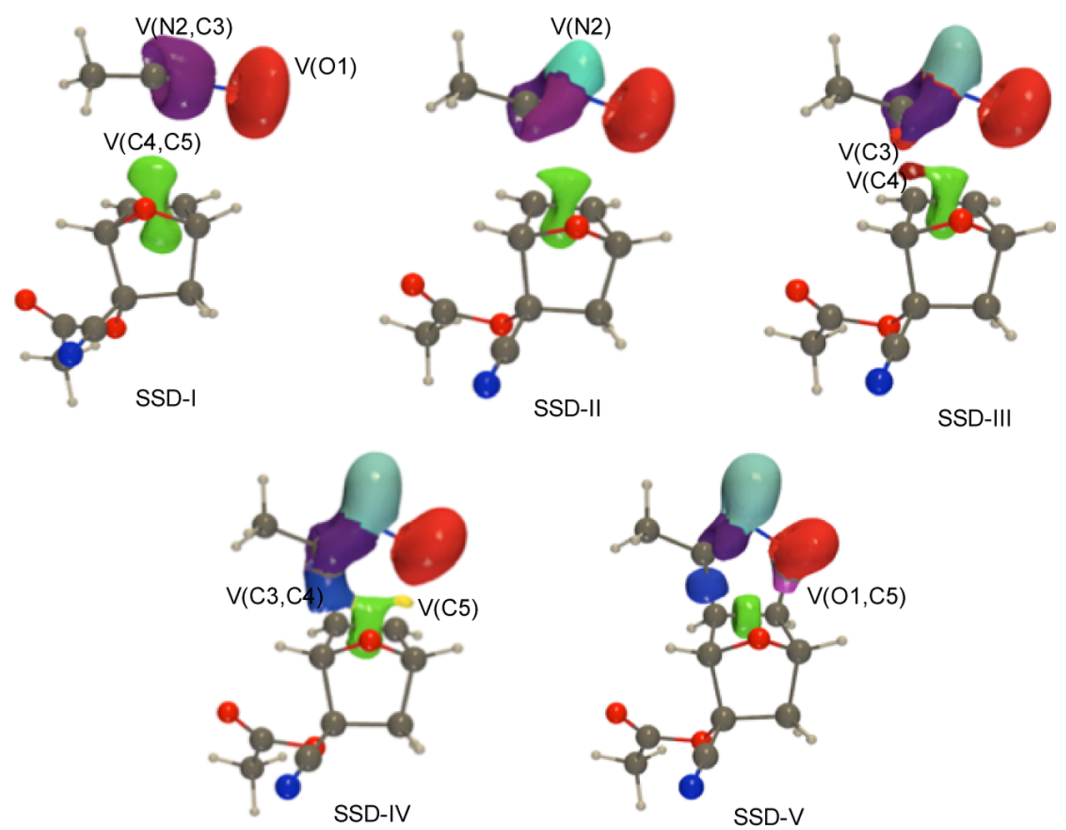

Figure 3. ELF basin isosurfaces $(\eta=0.7)$ for selected points that are representative of each of the SSDs found along the IRC associated with the TS-PSa regioisomeric channel.

Scheme 2. Curly Arrows Describing the Electronic Flows Observed along the Para-Syn Path of the Reaction between 1 and $2 a^{a}$

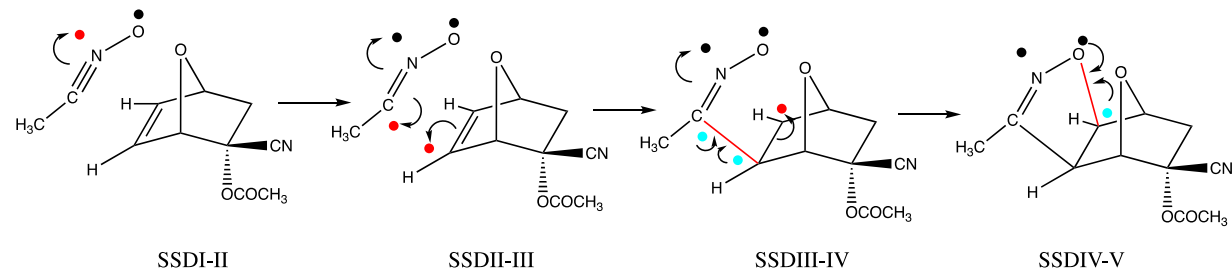

${ }^{a}$ In red, appearing basins. In blue, disappearing basins. The turning points between SSDs are indicated.

and 0.63 lel for $\mathrm{V}(\mathrm{C} 4)$. Once rich in electron density, these two monosynaptic basins give birth to the new $\mathrm{V}(\mathrm{C} 3, \mathrm{C} 4)$ disynaptic basin at the beginning of SSD-IV (see also Figure 3). This $\mathrm{V}(\mathrm{C} 3, \mathrm{C} 4)$ basin has a population of 1.43 lel and it reaches a population of $1.73 \mathrm{lel}$ at the end of the domain. The creation of the $\mathrm{V}(\mathrm{C} 5)$ monosynaptic basin is also noticed along the SSD-IV domain with a population varying between 0.19 and 0.31 lel. In the last domain (SSD-V), the fourth cusptype catastrophe takes place and results in the formation of the $\mathrm{C}-\mathrm{O}$ bond (as we can see in Figure 3). The population of the corresponding $\mathrm{V}(\mathrm{O} 1, \mathrm{C} 5)$ basin varies between 0.35 and $1.34 \mathrm{I}$ el along the SSD-V domain and is derived from the disappearance of the $\mathrm{V}(\mathrm{C5})$ basin and the reduction in the population of the $\mathrm{V}(\mathrm{O} 1)$ basin.

From the abovementioned results obtained from the analysis of the evolution of the populations of the different basins along the process, a curly arrow representation can be deduced, as shown in Scheme 2.

It is interesting to notice that the four turning points between the five SSDs found take place in a relatively narrow part of the IRC (see Figure 2), thus indicating that the topological changes take place in a rather synchronic way.

Using eqs $1-3$ of the Computational Methods section, Sy is calculated to be 0.93 and $\mathrm{Sy}^{\mathrm{abs}}=0.89$. This value implies that the topological changes take place in a very synchronous way, at $89 \%$ of the maximum absolute synchronicity. We can compare this value with the one obtained with the synchronicity definition by Cossio et al. ${ }^{70}$ that uses the Wiberg bond indices from the natural bond orbital analysis and is therefore based on the bond order evolution along the process. The synchronicity value obtained this way is 0.83 , very close to our absolute synchronicity. On the other hand, it should be noted that the TS can be found slightly displaced to the products along the IRC (at approximately 70\%), and therefore, it has a product-like character in terms of its position along the IRC pathway.

As we have shown, the $\mathrm{C}-\mathrm{C}$ bond is formed before the $\mathrm{O}-$ $\mathrm{C}$ one, although the oxygen atom of acetonitrile oxide is its most nucleophilic center. To this respect, it has been recently established $^{71}$ that in the $[3+2]$ cycloaddition reactions of $\mathrm{C}, \mathrm{N}$-dialkyl nitrones with nucleophilic ethylenes, the reaction begins with the formation of the $\mathrm{C}-\mathrm{C}$ single bond, while with strong electrophilic ethylenes, the reaction begins with the formation of the $\mathrm{C}-\mathrm{O}$ single bond. We have found that the dipolarophiles $\mathbf{2 a}, \mathbf{2 b}$, and $\mathbf{2 c}$ can be considered strong nucleophiles participating in the reaction and therefore the early formation of the $\mathrm{C}-\mathrm{C}$ single bond would be expected.

Mechanism of the Reaction between 1 and $\mathbf{2 b - c}$. The substitution of the hydrogen atom on $\mathrm{C} 5$ of $2 \mathrm{a}$ by the halogen one (chlorine and bromine) affected the electron flux along the reaction and more precisely the number of SSDs registered. In both cases, the number of SSDs is eight (see Figures 4-7). The main difference comes from the appearance of the $\mathrm{V}(\mathrm{C} 3)$ and $\mathrm{V}(\mathrm{C} 4)$ monosynaptic basins in the SSD-III and SSD-IV 


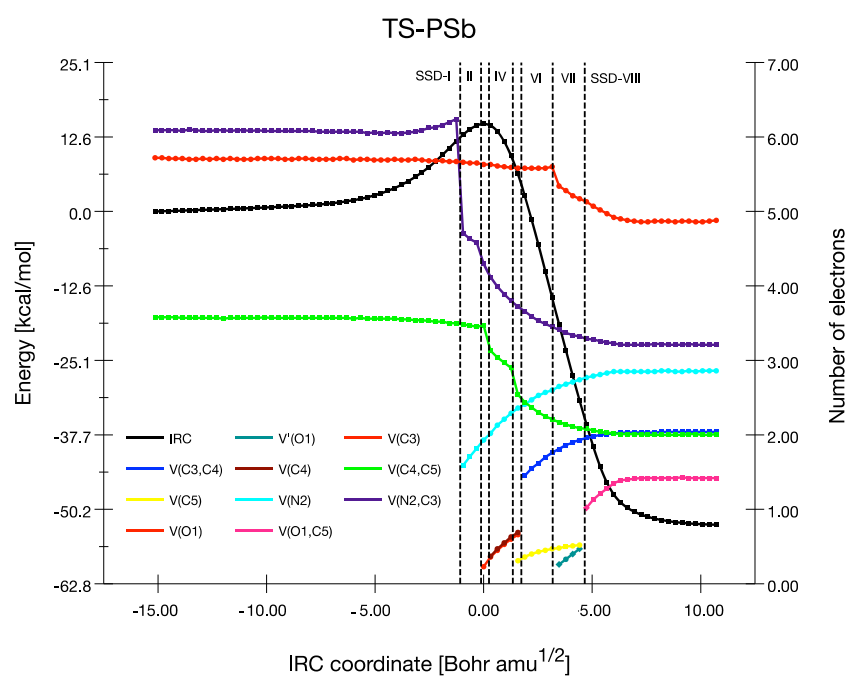

Figure 4. Population (in electrons) evolution of selected basins along the TS-PSb pathway of the reaction between $\mathbf{1}$ and $\mathbf{2} \mathbf{b}$.

(see Figure 5), compared to TS-PSa, where the two catastrophes took place in the same domain (SSD-III). Another difference lies in $\mathrm{V}(\mathrm{C} 5)$ and $\mathrm{V}(\mathrm{C} 3, \mathrm{C} 4)$, which in this case, appear in SSD-V and SSD-VI, respectively. In addition to these catastrophes, we note the creation of a second monosynaptic basin denoted $\mathrm{V}^{\prime}(\mathrm{O} 1)$ around the oxygen atom with populations of 0.26 and $0.24|e|$, respectively, in the two cases. This creation of the $\mathrm{V}^{\prime}(\mathrm{O} 1)$ basin corresponds to the sixth catastrophe (between SSD-VI and SSD-VII). These changes can be explained taking into account the electron-withdrawing effect of the halogen atom that delays the appearance of $\mathrm{V}(\mathrm{C} 4)$ and therefore two consecutive appearances of $\mathrm{V}(\mathrm{C} 3)$ and $\mathrm{V}(\mathrm{C} 4)$ take place. In addition, the late appearance of $\mathrm{V}(\mathrm{C} 4)$ delays the $\mathrm{V}(\mathrm{C} 3, \mathrm{C} 4)$ formation that takes place after the $\mathrm{V}(\mathrm{C5})$ basin appearance. Finally, the $\mathrm{V}(\mathrm{O} 1, \mathrm{C} 5)$ basin appears after a second monosynaptic basin $\mathrm{V}^{\prime}(\mathrm{O} 1)$ appears on the $\mathrm{O} 1$ atom may be also because of the electron-withdrawing effect of the halogen atom delaying the necessary population of $\mathrm{V}(\mathrm{C} 5)$. Importantly, one can see that in this case, the $\mathrm{C}-\mathrm{O}$ bond is formed from two monosynaptic

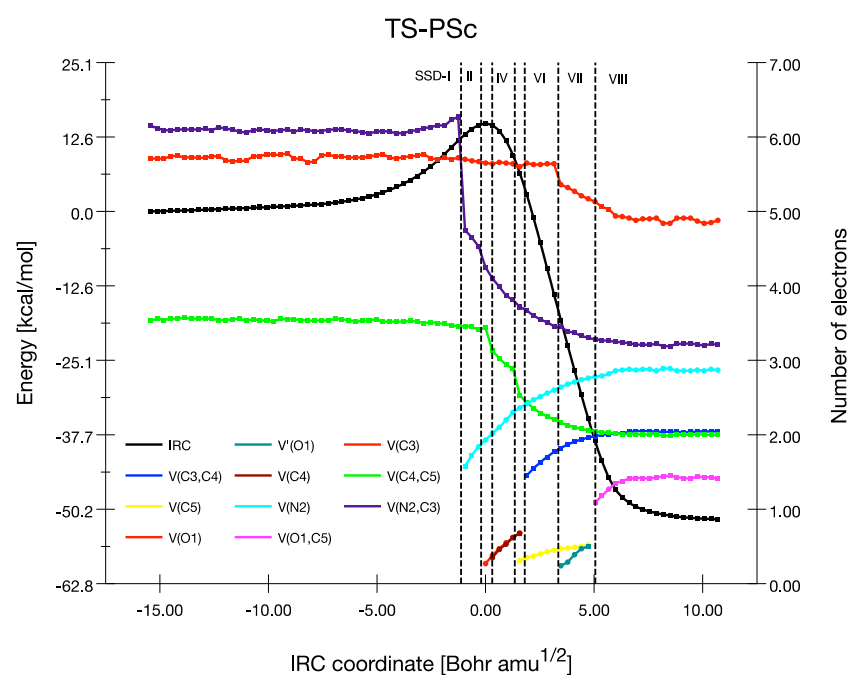

Figure 6. Population (in electrons) evolution of selected basins along the TS-PSc pathway of the reaction between 1 and $2 \mathrm{c}$.

basins, through a sharing model, instead of the well-known donating model currently established.

The last major change, the appearance of $\mathrm{V}(\mathrm{O} 1, \mathrm{C} 5)$, takes place very early along the pathway passing through TS-PSa $\left(R_{\mathrm{x}}\right.$ $=3.47 \mathrm{bohr} \mathrm{amu}^{1 / 2}$ ) compared with the TS-PSb and TS-PSc cases, in which the IRC value is 4.734 and $5.043 \mathrm{bohr} \mathrm{amu}^{1 / 2}$, respectively, when the turning point takes place. This early appearance of $\mathrm{V}(\mathrm{O} 1, \mathrm{C} 5)$ can be related to its low electronic population registered at the beginning of the SSD-V domain for the TS-PSa case $(0.35$ lel) compared to the TS-PSb and TS-PSc cases, in which the V(O1,C5) basin appears when its population is higher $(1.02$ and $1.09 \mid \mathrm{el})$. Furthermore, the $\mathrm{V}^{\prime}(\mathrm{O} 1)$ monosynaptic basin appears prior to the formation of the $\mathrm{O} 1-\mathrm{C} 5$ bond in the TS-PSb and TS-PSc cases.

The electronic flows, obtained from the analysis of the evolution of the populations of the different basins along the process, are depicted using curly arrow representation in Scheme 3.

The calculated values of Sy are 0.905 and 0.903 for TS-PSb and TS-PSc, respectively, and the Sy ${ }^{\text {abs }}$ values are 84 and $83 \%$,
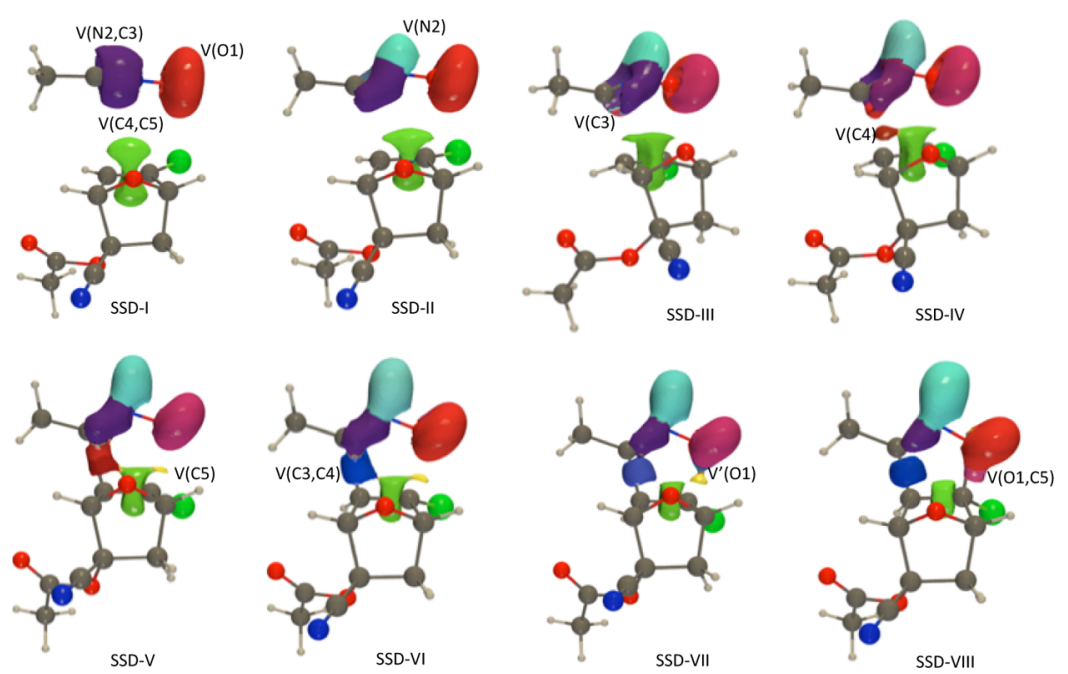

Figure 5. ELF basin isosurfaces $(\eta=0.7)$ for selected points that are representative of each of the SSDs found along the IRC associated with the TS-PSb regioisomeric channel. 

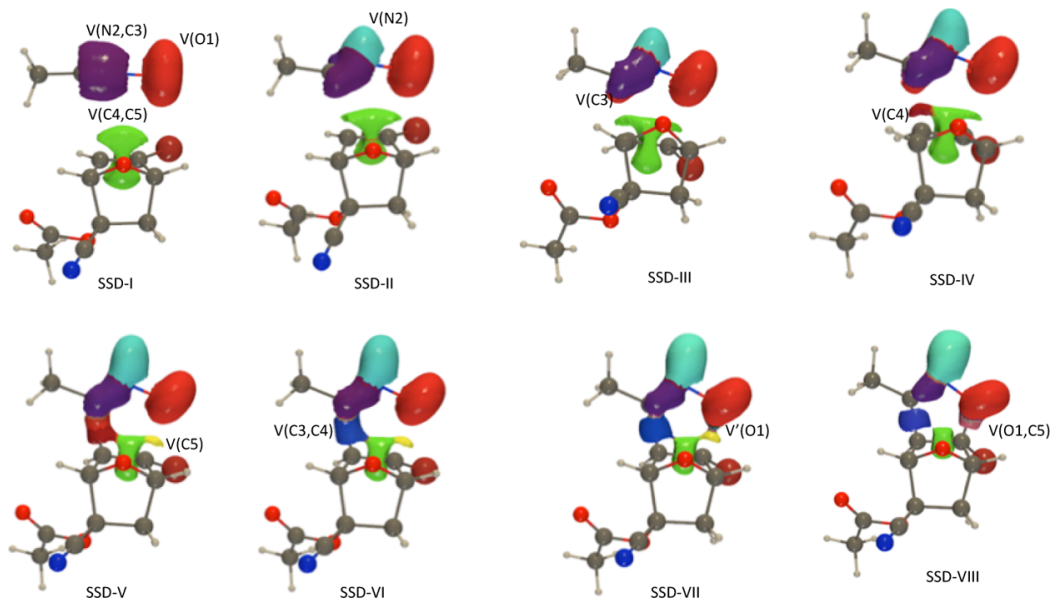

Figure 7. ELF basin isosurfaces $(\eta=0.7)$ for selected points that are representative of each of the SSDs found along the IRC associated with the TS-PSc regioisomeric channel.

Scheme 3. Curly Arrows Describing the Electronic Flows Observed along the Para-Syn Path of the Reaction between 1 and $2 b$ $(\mathrm{R}=\mathrm{Cl})$ or $2 \mathrm{c}(\mathrm{R}=\mathrm{Br})^{a}$

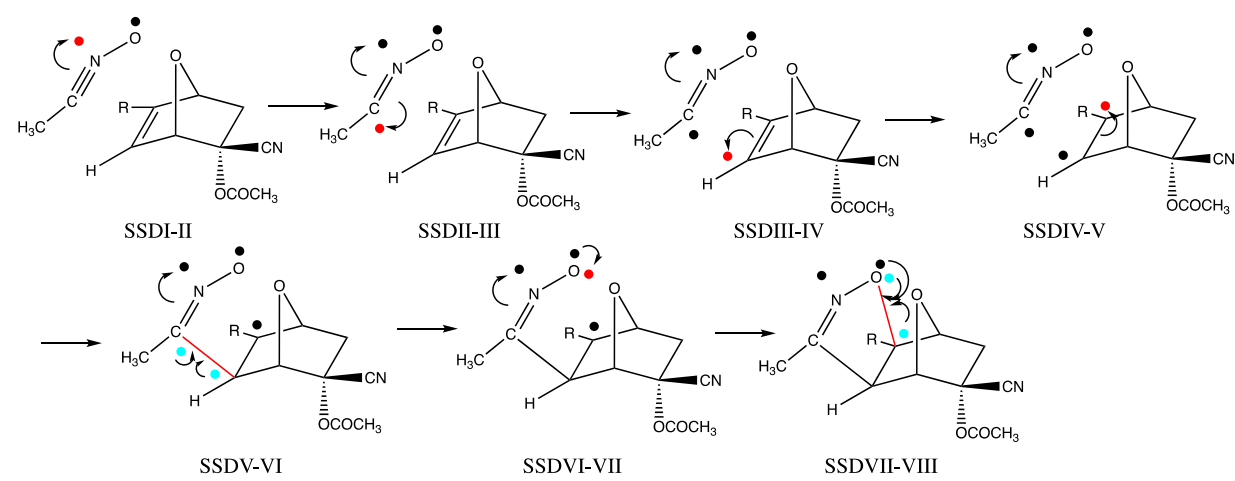

${ }^{a}$ The turning points between SSDs are indicated.

suggesting that the topological process is less synchronous during TS-PSb and TS-PSc compared to TS-PSa, $\left(\mathrm{Sy}^{\mathrm{abs}}=\right.$ 0.89). The same tendency is observed with the Cossio et al. ${ }^{70}$ synchronicity values: 0.79 and 0.78 for TS-PSb and TS-PSc, respectively, compared with 0.83 for TS-PSa.

We have also conducted a BET analysis for the syn attack along the meta channel that renders similar results to those shown above. See the Supporting Information for details.

\section{CONCLUSIONS}

The BET studies represent a way to advance in the chemical understanding of molecular mechanisms of chemical rearrangements, in the most fundamental manner beyond the molecular picture provided by the evolution of molecular orbitals, valence bond structures along the reaction progress, or conceptual density functional theory. BET is a rigorous way to recover the classical curly arrow representation and electron flow of molecular mechanisms. By deriving and analyzing the SSDs (from the ELF analysis) and turning points (from Thom's catastrophe theory), we can demonstrate where and how the chemical events, especially the bond-breaking/forming processes along the reaction pathway, take place. This approach can be considered as an alternative technique to $\mathrm{MO}, \mathrm{VB}$, and CDFT formalisms to further characterization of reaction mechanisms, focusing on the electron pair and bonding rearrangements involved in a given reaction.
The main conclusions of the present work can be summarized as follows:

We have found that the syn isomers are formed through lower energy barriers and are more stable than the corresponding anti isomers. Therefore, from either a kinetic or a thermodynamic point of view, they are the preferred products, in accordance with the experimental observations. On the other hand, the substitution of a $\mathrm{H}$ atom by a halogen ( $\mathrm{Cl}$ or $\mathrm{Br}$ ) disfavors the process. We have also found that the solvent benzene disfavors the processes, and the reaction energies are always slightly less negative in benzene than in vacuo.

The 12 TSs obtained show that the lengths of the $\mathrm{C}-\mathrm{C}$ forming bonds are generally shorter than the $\mathrm{C}-\mathrm{O}$-forming bonds, suggesting that the $\mathrm{C}-\mathrm{C}$ bonds are formed prior to the $\mathrm{C}-\mathrm{O}$ ones.

An analysis of the electron localization function associated to Thom's catastrophe theory within the BET was conducted for the syn reaction channels, which are the preferred processes. Along the reaction mechanism between $\mathbf{1}$ and $\mathbf{2 a}$, through the para and meta regioisomeric channels, the new $\mathrm{C}-\mathrm{C}$-forming bond always takes place before the $\mathrm{C}-\mathrm{O}$ ones, as expected from the geometric data of the TSs and from the order of appearance of the monosynaptic $\mathrm{V}(\mathrm{C})$ basins. This result is in agreement with the recently established ${ }^{71}$ order of $\mathrm{C}-\mathrm{C}$ and 
$\mathrm{C}-\mathrm{O}$ bond formation of nitrones reacting with nucleophilic ethylenes.

The substitution of the $\mathrm{C} 5-\mathrm{H}$ hydrogen atom of $2 \mathrm{a}$ by a halogen $(\mathrm{Cl}$ or $\mathrm{Br})$ increases the number of SSDs found during the reaction between $\mathbf{1}$ and $\mathbf{2 b}-\mathbf{c}$ because the electronwithdrawing effect of the halogen atom delays the appearance of $\mathrm{V}(\mathrm{C} 4)$ and the necessary population of $\mathrm{V}(\mathrm{C} 5)$. For the para regioisomeric pathway, eight SSDs have been found because of the creation of a new basin denoted as $\mathrm{V}^{\prime}(\mathrm{O} 1)$ and the subsequent appearance of different $\mathrm{V}(\mathrm{C})$ basins. During the meta pathway, six SSDs have been characterized because of the creation of $\mathrm{V}(\mathrm{C})$ monosynaptic basins before the $\mathrm{V}(\mathrm{C}, \mathrm{C})$ one. Interestingly, when a halogen is present, the $\mathrm{O}-\mathrm{C}$ bond is not formed along the para channel via the usual donating model from the oxygen lone pairs but with a sharing between $\mathrm{V}(\mathrm{C})$ and $\mathrm{V}^{\prime}(\mathrm{O})$ monosynaptic basins.

In spite of these differences that were observed, the mechanism can be summarized as follows: depopulation of the electron density at the $\mathrm{C}-\mathrm{N}$ triple bond and creation of the $\mathrm{V}(\mathrm{N})$ and $\mathrm{V}(\mathrm{C})$ basins, depopulation of the former $\mathrm{C}-\mathrm{C}$ double bond with the creation of $\mathrm{V}(\mathrm{C})$ basins, creation of $\mathrm{V}(\mathrm{C}, \mathrm{C})$ basins associated to the $\mathrm{C}-\mathrm{C}$ bond, and final formation of the $\mathrm{V}(\mathrm{O}, \mathrm{C})$ basin associated to the $\mathrm{O}-\mathrm{C}$ bond through different mechanisms depending on the presence of a halogen atom. We have found that all these topological changes take place in a highly synchronous way: the absolute synchronicity ranges between 83 and $89 \%$ of the maximum absolute synchronicity.

\section{COMPUTATIONAL METHODS}

All geometry optimizations were performed using the Gaussian 16 program. ${ }^{72}$ The geometries of the stationary points were fully optimized through DFT calculations using the $\omega$ B97X$\mathrm{D}^{73}$ functional with the $6-311 \mathrm{G}(\mathrm{d})$ basis set. The stationary points were characterized by frequency calculations in order to verify the number of imaginary frequencies (zero for local minima and one for transition state (TS) structures). The IRC paths were computed using the second-order GonzálezSchlegel integration method ${ }^{74,75}$ in order to obtain the energy profiles connecting each TS structure to the two associated minima of the corresponding path. The solvent effects of benzene were considered using the integral equation formalism of the polarizable continuum model (IEFPCM) ${ }^{76}$ in the framework of the self-consistent reaction field (SCRF).

In the BET analysis, the wave function was obtained for each point of the IRCs and the ELF analysis was performed by means of the TopMod package ${ }^{77}$ considering a cubical grid with a step size smaller than 0.2 bohr. The visualization of ELF basin positions was performed using the DrawMol ${ }^{78}$ and DrawProfile codes. $^{79}$

The position of the changes between the different SSDs derived from the BET analysis is employed as an indicator of the synchronicity of a particular process, as was previously defined $^{69,80}$

$$
\text { Sy }=1-\frac{2}{n(n-1)\left(S_{\mathrm{f}}-S_{0}\right)} \sum_{i=1}^{n} \sum_{j=i+1}^{n}\left(S_{j}-S_{i}\right)
$$

Equation 1 is used to calculate the synchronicity (Sy) of the process, its maximum value being 1 . In this equation, $n$ is the number of SSDs minus one, $S_{\mathrm{f}}$ and $S_{0}$ are the final and initial IRC values, respectively, and the different values of $S_{j}$ and $S_{i}$ are the IRC values at which the turning points between SSDs appear. The minimum value of Sy is a function of $n$ and can be obtained using eq 2

$$
\operatorname{Sy}^{\min }=1-\frac{2\left(\sum_{i=1}^{n}(n-i)-\sum_{i=1}^{n / 2}(n-2 i)\right)}{n(n-1)}
$$

The absolute synchronicity, $\mathrm{Sy}^{\mathrm{abs}}$, on a zero-to-one scale, is obtained using eq 3

$$
S y^{a b s}=\frac{S y-S y^{\min }}{1-S y^{\min }}
$$

\section{ASSOCIATED CONTENT}

\section{Supporting Information}

The Supporting Information is available free of charge at https://pubs.acs.org/doi/10.1021/acsomega.0c02371.

Electronic energies; thermodynamic parameters; relative enthalpies, Gibbs energies, and entropies; basin populations and IRC coordinates of some points along the IRC passing through TS-PSa, TS-PSb, TS-PSc, TSMSa, TS-MSb, and TS-MSc; CDFT analysis of the processes; $\mathrm{BET}$ analysis for the syn attack along the meta channel; and Cartesian coordinates of the stationary points found (PDF)

\section{AUTHOR INFORMATION}

\section{Corresponding Authors}

Ibrahim Mbouombouo Ndassa - Computational Chemistry Laboratory, High Teacher Training College, University of Yaoundé 1, Yaoundé, Cameroon; Email: indassa@yahoo.fr

Vicent Sixte Safont - Departament de Química Física $i$ Analítica, Universitat Jaume I, 12071 Castello, Spain; 이이.org/0000-0003-2709-4230; Email: safont@uji.es

\section{Authors}

Abel Idrice Adjieufack - Physical and Theoretical Chemistry Laboratory and Computational Chemistry Laboratory, High Teacher Training College, University of Yaoundé 1, Yaounde, Cameroon

Cyrille Nouhou Nana - Physical and Theoretical Chemistry Laboratory and Computational Chemistry Laboratory, High Teacher Training College, University of Yaoundé 1, Yaounde, Cameroon

Joseph Ketcha-Mbadcam - Physical and Theoretical Chemistry Laboratory, University of Yaounde 1, Yaounde, Cameroon

Juan Andrés - Departament de Química Física i Analítica, Universitat Jaume I, 12071 Castelló, Spain; 이이.org/ 0000-0003-0232-3957

Mónica Oliva - Departament de Química Física i Analítica, Universitat Jaume I, 12071 Castelló, Spain; 이이.org/ 0000-0001-6651-7852

Complete contact information is available at: https://pubs.acs.org/10.1021/acsomega.0c02371

\section{Notes}

The authors declare no competing financial interest.

\section{ACKNOWLEDGMENTS}

Authors gratefully thank the Consortium des Équipements de Calcul Intensif (CÉCI, http://www.ceci-hpc.be) and particularly the Technological Platform of High-Performance 
Computing for all calculations through financial support from the FNRS-FRFC, of the Walloon Region, and of the University of Namur (Conventions no. 2.5020.11, GEQ U.G006.15, 1610468, and RW/GEQ2016). A.I.A. thanks the University of Namur (Belgium) for his UNamur-CERUNA Ph.D. Mobility Fellowship. J.A., M.O., and V.S.S. acknowledge Universitat Jaume I for project UJI-B2019-30 and Ministerio de Ciencia, Innovación y Universidades (Spain) project PGC2018094417-B-I00 for supporting this research financially.

\section{REFERENCES}

(1) Yang, Z.; Jamieson, C. S.; Xue, X.-S.; Garcia-Borràs, M.; Benton, T.; Dong, X.; Liu, F.; Houk, K. N. Mechanisms and Dynamics of Reactions Involving Entropic Intermediates. Trends Chem. 2019, 1, 22-34.

(2) El Hage, K.; Brickel, S.; Hermelin, S.; Gaulier, G.; Schmidt, C.; Bonacina, L.; van Keulen, S. C.; Bhattacharyya, S.; Chergui, M.; Hamm, P.; Rothlisberger, U.; Wolf, J.-P.; Meuwly, M. Implications of short time scale dynamics on long time processes. Struct. Dyn. 2017, 4, 061507.

(3) Woodward, R. B.; Hoffmann, R. Stereochemistry of electrocyclic reactions. J. Am. Chem. Soc. 1965, 87, 395-397.

(4) Woodward, R. B.; Hoffmann, R. Selection Rules for Sigmatropic Reactions. J. Am. Chem. Soc. 1965, 87, 2511-2513.

(5) Hoffmann, R.; Woodward, R. B. Conservation of orbital symmetry. Acc. Chem. Res. 1968, 1, 17-22.

(6) Harcourt, R. D. Increased-valence structures and some valence bond representations for reaction mechanisms. J. Mol. Struct.: THEOCHEM 1997, 398-399, 93-100.

(7) Shaik, S.; Hiberty, P. C. Valence bond theory, its history, fundaments, and applications: A primer. In Reviews in Computational Chemistry; Lipkowitz, K. B., Larter, R., Cundari, T. R., Eds.; WileyVCH: Hoboken, New Jersey, 2004; Vol. 20.

(8) Hiberty, P. C.; Shaik, S. A survey of recent developments in ab initio valence bond theory. J. Comput. Chem. 2007, 28, 137-151.

(9) Parr, R. G.; Yang, W. Density Functional Theory of Atoms and Molecules; Oxford University Press and Clarendon Press: New York and Oxford, 1989.

(10) Parr, R. G.; Yang, W. Density-Functional Theory of the Electronic Structure of Molecules. Annu. Rev. Phys. Chem. 1995, 46, 701-728.

(11) Geerlings, P.; De Proft, F.; Langenaeker, W. Conceptual Density Functional Theory. Chem. Rev. 2003, 103, 1793-1874.

(12) Minerva, T.; Sicilia, E.; Russo, N. Density-Functional Approach to Hardness Evaluation and Its Use in the Study of the Maximum Hardness Principle. J. Am. Chem. Soc. 1998, 120, 9053-9058.

(13) Pham, B. Q.; Gordon, M. S. Can Orbitals Really Be Observed in Scanning Tunneling Microscopy Experiments? J. Phys. Chem. A 2017, 121, 4851-4852.

(14) Kerridge, A. Quantification of f-element covalency through analysis of the electron density: insights from simulation. Chem. Commun. 2017, 53, 6685-6695.

(15) Boys, S. F. Localized orbitals and localized adjustment functions. In Quantum Theory of Atoms, Molecules, and the Solid State; Löwdin, P. O., Ed.; Academic: New York: New York, 1966; pp 253-262.

(16) Caldwell, D.; Redington, P.; Eyring, H. Density matrix method for orbital localization. Proc. Natl. Acad. Sci. U.S.A. 1979, 76, 30423045.

(17) Pipek, J.; Mezey, P. G. A fast intrinsic localization procedure applicable for $\mathrm{ab}$ initio and semiempirical linear combination of atomic orbital wave functions. J. Chem. Phys. 1989, 90, 4916-4926.

(18) Reed, A. E.; Curtiss, L. A.; Weinhold, F. Intermolecular Interactions from a Natural Bond Orbital, Donor-Acceptor Viewpoint. Chem. Rev. 1988, 88, 899-926.

(19) Ayers, P. L.; Boyd, R. J.; Bultinck, P.; Caffarel, M.; CarbóDorca, R.; Causá, M.; Cioslowski, J.; Contreras-García, J.; Cooper, D. L.; Coppens, P.; Gatti, C.; Grabowsky, S.; Lazzeretti, P.; Macchi, P.;
Martín Pendás, Á.; Popelier, P. L. A.; Ruedenberg, K.; Rzepa, H.; Savin, A.; Sax, A.; Schwarz, W. H. E.; Shahbazian, S.; Silvi, B.; Solà, M.; Tsirelson, V. Six questions on topology in theoretical chemistry. Comput. Theor. Chem. 2015, 1053, 2-16.

(20) Andrés, J.; Ayers, P. W.; Boto, R. A.; Carbó-Dorca, R.; Chermette, H.; Cioslowski, J.; Contreras-García, J.; Cooper, D. L.; Frenking, G.; Gatti, C.; Heidar-Zadeh, F.; Joubert, L.; Martín Pendás, Á.; Matito, E.; Mayer, I.; Misquitta, A. J.; Mo, Y.; Pilmé, J.; Popelier, P. L. A.; Rahm, M.; Ramos-Cordoba, E.; Salvador, P.; Schwarz, W. H. E.; Shahbazian, S.; Silvi, B.; Solà, M.; Szalewicz, K.; Tognetti, V.; Weinhold, F.; Zins, É. L. Nine questions on energy decomposition analysis. J. Comput. Chem. 2019, 40, 2248-2283.

(21) Popelier, P. L. A. Intermolecular Forces and Clusters I; Springer: Berlin Heidelberg, 2005.

(22) Popelier, P. L. A. Quantum Chemical Topology; Springer International Publishing, 2016.

(23) Bader, R. F. W. Atoms in Molecules. A Quantum Theory; Cambridge University Press: Oxford U.K., 1991.

(24) Bader, R. F. W. Atoms in molecules. In The Encyclopedia of Computational Chemistry; Schleyer, P. v. R., Alinger, N. L., Clark, T., Gasteiger, J., Kollman, P. A., Schaefer, H. F., III, Schreiner, P. R., Eds.; Wiley: Chichester, 1998.

(25) Becke, A. D.; Edgecombe, K. E. A Simple Measure of Electron Localization in Atomic and Molecular Systems. J. Chem. Phys. 1990, 92, 5397-5403.

(26) Silvi, B.; Savin, A. Classification of Chemical Bonds Based on Topological Analysis of Electron Localization Functions. Nature 1994, 371, 683-686.

(27) Gillespie, R. J.; Robinson, E. A.; Gilbert, N. Gilbert N. Lewis and the chemical bond: The electron pair and the octet rule from 1916 to the present day. J. Comput. Chem. 2007, 28, 87-97.

(28) Savin, A.; Jepsen, O.; Flad, J.; Andersen, O. K.; Preuss, H.; von Schnering, H. G. Electron Localization in Solid-state Structures of the Elements: the Diamond Structure. Angew. Chem., Int. Ed. 1992, 31, 187-188.

(29) Krokidis, X.; Noury, S.; Silvi, B. Characterization of Elementary Chemical Processes by Catastrophe Theory. J. Phys. Chem. A 1997, 101, 7277-7282.

(30) Becke, A. D. Density-functional thermochemistry. III. The role of exact exchange. J. Chem. Phys. 1993, 98, 5648-5652.

(31) Thom, R. Structural Stability and Morphogenesis, an Outline of a General Theory of Models; Benjamin/Cummings Publishing Co: Reading, Mass, 1980.

(32) Andrés, J.; González-Navarrete, P.; Safont, V. S.; Silvi, B. Curly arrows, Electron Flow, and Reaction Mechanisms from the Perspective of the Bonding Evolution Theory. Phys. Chem. Chem. Phys. 2017, 19, 29031-29046.

(33) Polo, V.; Andres, J.; Berski, S.; Domingo, L. R.; Silvi, B. Understanding Reaction Mechanisms in Organic Chemistry from Catastrophe Theory Applied to the Electron Localization Function Topology. J. Phys. Chem. A 2008, 112, 7128-7136.

(34) Andrés, J.; González-Navarrete, P.; Safont, V. S. Unraveling reaction mechanisms by means of Quantum Chemical Topology Analysis. Int. J. Quantum Chem. 2014, 114, 1239-1252.

(35) Polo, V.; Andrés, J. A joint study based on the electron localization function and catastrophe theory of the chameleonic and centauric models for the Cope rearrangement of 1,5-hexadiene and its cyano derivatives. J. Comput. Chem. 2005, 26, 1427-1437.

(36) Andrés, J.; Gracia, L.; González-Navarrete, P.; Safont, V. S. Chemical structure and reactivity by means of quantum chemical topology analysis. Comput. Theor. Chem. 2015, 1053, 17-30.

(37) Polo, V.; Gonzalez-Navarrete, P.; Silvi, B.; Andres, J. An electron localization function and catastrophe theory analysis on the molecular mechanism of gas-phase identity SN2 reactions. Theor. Chem. Acc. 2008, 120, 341-349.

(38) Andrés, J.; Berski, S.; Contreras-García, J.; González-Navarrete, P. Following the Molecular Mechanism for the $\mathrm{NH} 3+\mathrm{LiH} \rightarrow \mathrm{LiNH} 2$ $+\mathrm{H} 2$ Chemical Reaction: A Study Based on the Joint Use of the 
Quantum Theory of Atoms in Molecules (QTAIM) and Noncovalent Interaction (NCI) Index. J. Phys. Chem. A 2014, 118, 1663-1672.

(39) González-Navarrete, P.; Domingo, L. R.; Andrés, J.; Berski, S.; Silvi, B. Electronic fluxes during diels-alder reactions involving 1,2benzoquinones: mechanistic insights from the analysis of electron localization function and catastrophe theory. J. Comput. Chem. 2012, 33, 2400-2411.

(40) Zahedi, E.; Shaabani, S.; Shiroudi, A. Following the Molecular Mechanism of Decarbonylation of Unsaturated Cyclic Ketones Using Bonding Evolution Theory Coupled with NCI Analysis. J. Phys. Chem. A 2017, 121, 8504-8517.

(41) Keley, V.; Zahedi, E. Understanding the kinetics and molecular mechanism of unimolecular gas phase thermal decomposition of the $\alpha$-ketoester methyl benzoylformate using RRKM and BET theories. $J$. Mol. Graph. Model. 2019, 87, 22-29.

(42) Nouri, A.; Zahedi, E.; Ehsani, M.; Nouri, A.; Balali, E. Understanding the molecular mechanism of thio-Claisen rearrangement of allyl phenyl sulfide and allyl vinyl sulfide using bonding evolution theory coupled with NCI analysis. J. Sulf. Chem. 2018, 39, $350-366$

(43) Polo, V.; Andres, J.; Castillo, R.; Berski, S.; Silvi, B. Understanding the Molecular Mechanism of the 1,3-Dipolar Cycloaddition between Fulminic Acid and Acetylene in Terms of the Electron Localization Function and Catastrophe Theory. Chem.-Eur. J. 2004, 10, 5165-5172.

(44) Gonzalez-Navarrete, P.; Andres, J.; Safont, V. S. A bonding evolution analysis for the thermal Claisen rearrangement: an experimental and theoretical exercise for testing the electron density flow. Phys. Chem. Chem. Phys. 2018, 20, 535-541.

(45) Viciano, I.; González-Navarrete, P.; Andrés, J.; Martí, S. Joint Use of Bonding Evolution Theory and QM/MM Hybrid Method for Understanding the Hydrogen Abstraction Mechanism via Cytochrome P450 Aromatase. J. Chem. Theory Comput. 2015, 11, 14701480.

(46) Safont, V. S.; González-Navarrete, P.; Oliva, M.; Andrés, J. Inquiry of the electron density transfers in chemical reactions: a complete reaction path for the denitrogenation process of 2,3diazabicyclo[2.2.1]hept-2-ene derivatives. Phys. Chem. Chem. Phys. 2015, 17, 32358-32374.

(47) González-Navarrete, P.; Sensato, F. R.; Andrés, J.; Longo, E. Oxygen Atom Transfer Reactions from Mimoun Complexes to Sulfides and Sulfoxides. A Bonding Evolution Theory Analysis. J. Phys. Chem. A 2014, 118, 6092-6103.

(48) González-Navarrete, P.; Andrés, J.; Berski, S. How a Quantum Chemical Topology Analysis Enables Prediction of Electron Density Transfers in Chemical Reactions. The Degenerated Cope Rearrangement of Semibullvalene. J. Phys. Chem. Lett. 2012, 3, 2500-2505.

(49) Andrés, J.; Berski, S.; Domingo, L. R.; González-Navarrete, P. Nature of the ring-closure process along the rearrangement of octa1,3,5,7-tetraene to cycloocta-1,3,5-triene from the perspective of the electron localization function and catastrophe theory. J. Comput. Chem. 2012, 33, 748-756.

(50) Gillet, N.; Chaudret, R.; Contreras-García, J.; Yang, W.; Silvi, B.; Piquemal, J.-P. Coupling Quantum Interpretative Techniques: Another Look at Chemical Mechanisms in Organic Reactions. J. Chem. Theory Comput. 2012, 8, 3993-3997.

(51) Fang, D.; Chaudret, R.; Piquemal, J.-P.; Cisneros, G. A. Toward a deeper understanding of enzyme reactions using the coupled ELF/ NCI analysis: Application to DNA repair enzymes. J. Chem. Theory Comput. 2013, 9, 2156-2160.

(52) de Courcy, B.; Derat, E.; Piquemal, J.-P. Bridging organometallics and quantum chemical topology: Understanding electronic relocalisation during palladium-catalyzed reductive elimination. J. Comput. Chem. 2015, 36, 1167-1175.

(53) Oliva, M.; Safont, V. S.; González-Navarrete, P.; Andrés, J. Electronic structure and rearrangements of anionic $\left[\mathrm{ClMg}\left(\eta^{2}-\mathrm{O}_{2} \mathrm{C}\right)\right]^{-}$ and $\left[\mathrm{ClMg}\left(\eta^{2}-\mathrm{CO}_{2}\right)\right]^{-}$complexes: a quantum chemical topology study. Theor. Chem. Acc. 2017, 136, 51.
(54) Andrés, J.; Gracia, L.; Gonzalez-Navarrete, P.; Safont, V. S. Quantum Chemical Topology Approach for Dissecting Chemical Structure and Reactivity. In Applications of Topological Methods in Molecular Chemistry; Chauvin, R., Lepetit, C., Silvi, B., Alikhani, E., Eds.; Springer: Berlin, 2016; Vol. 22, pp 257-294.

(55) Merino, P.; Chiacchio, M. A.; Legnani, L.; Delso, I.; Tejero, T. Introducing topology to assess the synchronicity of organic reactions. Dual reactivity of oximes with alkenes as a case study. Org. Chem. Front. 2017, 4, 1541-1554.

(56) Munárriz, J.; Laplaza, R.; Polo, V. A bonding evolution theory study on the catalytic Noyori hydrogenation reaction. Mol. Phys. 2019, 117, 1315-1324.

(57) Chamorro, E.; Rincón, E. Unraveling the sequence of the electronic flow along the water-assisted ring-opening reaction in mutagen MX. Theor. Chem. Acc. 2019, 138, 3.

(58) Chamorro, E.; Prado, Y.; Duque-Noreña, M.; GutiérrezSánchez, N.; Rincón, E. Understanding the sequence of the electronic flow along the $\mathrm{HCN} / \mathrm{CNH}$ isomerization within a bonding evolution theory quantum topological framework. Theor. Chem. Acc. 2019, 138, 60.

(59) Ríos-Gutiérrez, M.; Pérez, P.; Domingo, L. R. A bonding evolution theory study of the mechanism of $[3+2]$ cycloaddition reactions of nitrones with electron-deficient ethylenes. RSC $A d v$. 2015, 5, 58464-58477.

(60) Ríos-Gutiérrez, M.; Domingo, L. R. Unravelling the Mysteries of the [3+2] Cycloaddition Reactions. Eur. J. Org. Chem. 2019, 267282

(61) Adjieufack, A. I.; Ndassa, I. M.; Ketcha Mbadcam, J.; RíosGutiérrez, M.; Domingo, L. R. Steric interactions controlling the syn diastereofacial selectivity in the $[3+2]$ cycloaddition reaction between acetonitrile oxide and 7-oxanorborn-5-en-2-ones: A molecular electron density theory study. J. Phys. Org. Chem. 2017, 30, No. e3710.

(62) Domingo, L. R.; Emamian, S.; Salami, M.; Ríos-Gutiérrez, M. Understanding the molecular mechanism of the $[3+2]$ cycloaddition reaction of benzonitrile oxide toward electron-richN-vinylpyrrole: a DFT study. J. Phys. Org. Chem. 2016, 29, 368-376.

(63) Domingo, L. R. A New C-C Bond Formation Model Based on the Quantum Chemical Topology of Electron Density. RSC Adv. 2014, 4, 32415-32428.

(64) Ndassa, I. M.; Adjieufack, A. I.; Mbadcam Ketcha, J.; Berski, S.; Ríos-Gutiérrez, M.; Domingo, L. R. Understanding the reactivity and regioselectivity of $[3+2]$ cycloaddition reactions between substituted nitrile oxides and methyl acrylate. A molecular electron density theory study. Int. J. Quantum Chem. 2017, 117, No. e25451.

(65) Emamian, S.; Lu, T.; Domingo, L. R.; Heidarpoor Saremi, L.; Ríos-Gutiérrez, M. A molecular electron density theory study of the chemo- and regioselective $[3+2]$ cycloaddition reactions between trifluoroacetonitrile N-oxide and thioketones. Chem. Phys. 2018, 501, $128-137$.

(66) Zeroual, A.; Ríos-Gutiérrez, M.; El Idrissi, M.; El Alaoui El Abdallaoui, H.; Domingo, L. R. An MEDT study of the mechanism and selectivities of the [3+2] cycloaddition reaction of tomentosin with benzonitrile oxide. Int. J. Quantum Chem. 2019, 119, No. e25980.

(67) Ríos-Gutiérrez, M.; Domingo, L. R.; Esseffar, M. h.; Oubella, A.; Ait Itto, M. Y. Unveiling the Different Chemical Reactivity of Diphenyl Nitrilimine and Phenyl Nitrile Oxide in [3+2] Cycloaddition Reactions with (R)-Carvone through the Molecular Electron Density Theory. Molecules 2020, 25, 1085.

(68) Arjona, O.; de Dios, A.; la Pradilla, R. F. d.; Mallo, A.; Plumet, J. Polar vs steric effects in the 1,3-dipolar cycloaddition reactions of acetonitrile oxide and 2-endO-acetoxy-5-halo-7-oxabicyclo[2.2.1]hept-5-en-2-exo-carbonitrile. Tetrahedron 1990, 46, 8179-8186.

(69) Adjieufack, A. I.; Mbah Bake, M.; Ketcha Mbadcam, J.; Mbouombouo Ndassa, I.; Andrés, J.; Oliva, M.; Safont, V. S. How effectively bonding evolution theory retrieves and visualizes curly arrows: The cycloaddition reaction of cyclic nitrones. Int. J. Quantum Chem. 2019, 119, No. e25985. 
(70) Lecea, B.; Arrieta, A.; Lopez, X.; Ugalde, J. M.; Cossío, F. P. On the Stereochemical Outcome of the Catalyzed and Uncatalyzed Cycloaddition Reaction between Activated Ketenes and Aldehydes to form cis- and trans-2-Oxetanones. An ab Initio Study. J. Am. Chem. Soc. 1995, 117, 12314-12321.

(71) Domingo, L. R.; Ríos-Gutiérrez, M.; Pérez, P. A Molecular Electron Density Theory Study of the Reactivity and Selectivities in [3 + 2] Cycloaddition Reactions of C,N-Dialkyl Nitrones with Ethylene Derivatives. J. Org. Chem. 2018, 83, 2182-2197.

(72) Frisch, M. J.; Trucks, G. W.; Schlegel, H. B.; Scuseria, G. E.; Robb, M. A.; Cheeseman, J. R.; Scalmani, G.; Barone, V.; Petersson, G. A.; Nakatsuji, H.; Li, X.; Caricato, M.; Marenich, A. V.; Bloino, J.; Janesko, B. G.; Gomperts, R.; Mennucci, B.; Hratchian, H. P.; Ortiz, J. V.; Izmaylov, A. F.; Sonnenberg, J. L.; Williams; Ding, F.; Lipparini, F.; Egidi, F.; Goings, J.; Peng, B.; Petrone, A.; Henderson, T.; Ranasinghe, D.; Zakrzewski, V. G.; Gao, J.; Rega, N.; Zheng, G.; Liang, W.; Hada, M.; Ehara, M.; Toyota, K.; Fukuda, R.; Hasegawa, J.; Ishida, M.; Nakajima, T.; Honda, Y.; Kitao, O.; Nakai, H.; Vreven, T.; Throssell, K.; Montgomery, J. A., Jr; Peralta, J. E.; Ogliaro, F.; Bearpark, M. J.; Heyd, J. J.; Brothers, E. N.; Kudin, K. N.; Staroverov, V. N.; Keith, T. A.; Kobayashi, R.; Normand, J.; Raghavachari, K.; Rendell, A. P.; Burant, J. C.; Iyengar, S. S.; Tomasi, J.; Cossi, M.; Millam, J. M.; Klene, M.; Adamo, C.; Cammi, R.; Ochterski, J. W.; Martin, R. L.; Morokuma, K.; Farkas, O.; Foresman, J. B.; Fox, D. J. Gaussian 16 Rev. C01; Gaussian, Inc.: Wallingford, CT, 2016.

(73) Chai, J.-D.; Head-Gordon, M. Long-range Corrected Hybrid Density Functionals with Damped Atom-Atom Dispersion Corrections. Phys. Chem. Chem. Phys. 2008, 10, 6615-6620.

(74) Gonzalez, C.; Schlegel, H. B. Reaction path following in massweighted internal coordinates. J. Phys. Chem. 1990, 94, 5523-5527.

(75) Gonzalez, C.; Schlegel, H. B. Improved algorithms for reaction path following: Higher-order implicit algorithms. J. Chem. Phys. 1991, 95, 5853-5860.

(76) Tomasi, J.; Mennucci, B.; Cammi, R. Quantum Mechanical Continuum Solvation Models. Chem. Rev. 2005, 105, 2999-3094.

(77) Noury, S.; Krokidis, X.; Fuster, F.; Silvi, B. Computational Tools for the Electron Localization Function Topological Analysis. Comput. Chem. 1999, 23, 597-604.

(78) Liégeois, V. UNamur, DrawMol. 2018, www.unamur.be/ drawmol .

(79) Liégeois, V. UNamur, DrawProfile. 2018, www.unamur.be/ drawprofile.

(80) Adjieufack, A. I.; Ndassa, I. M.; Patouossa, I.; Mbadcam, J. K.; Safont, V. S.; Oliva, M.; Andrés, J. On the outside looking in: rethinking the molecular mechanism of 1,3-dipolar cycloadditions from the perspective of bonding evolution theory. The reaction between cyclic nitrones and ethyl acrylate. Phys. Chem. Chem. Phys. 2017, 19, 18288-18302. 